\title{
SHH Negative
}

National Cancer Institute

\section{Source}

National Cancer Institute. SHH Negative. NCI Thesaurus. Code C141281.

An indication that $\mathrm{SHH}$ expression has not been detected in a sample. 